\title{
ECF with Infusional Fluorouracil for 5 Days in Locally Advanced and Metastatic Gastric Cancer, Is It Better than the Standard?
}

\author{
Abeer Ibrahim ${ }^{1}$, Adel Gabr ${ }^{1} \&$ Ahmed Hefny ${ }^{1}$ \\ ${ }^{1}$ Medical Oncology Department, South Egypt Cancer Institute, Assiut University, Assiut, Egypt \\ Correspondence: Abeer Ibrahim, Medical Oncology Department, South Egypt Cancer Institute, Assiut \\ University, Assiut, Egypt. E-mail: ab_elsayed2003@yahoo.com
}

Received: March 4, $2013 \quad$ Accepted: April 2, $2013 \quad$ Online Published: April 23, 2013
doi:10.5539/cco.v2n1p136 URL: http://dx.doi.org/10.5539/cco.v2n1p136

\begin{abstract}
The ECF (Epirubcin/Cisplatin/5-fluorouracil) first therapy in metastatic gastric is the optimal therapeutic option but its complexity limits its utility in many communities. We investigated a more convenient modification of the standard approach, "5 days CIV 5-fluorouracil $1000 \mathrm{mg} / \mathrm{m}^{2}$ ". A total of 115 patients with advanced and metastatic adenocarcinoma of the stomach and gastroesophageal cancer were reviewed retrospectively to compare the efficacy of modified ECF $\mathrm{N}=41$ with the reference protocols FAM N=32 and ELF $\mathrm{N}=42$. The overall response rate was $36.5 \%$ with ECF, $16.6 \%$ with ELF, and $15.6 \%$ with FAM, with significant differences $p=0.001$. No one achieved a complete tumor regression. However, 4 patients with locally advanced stomach were able to have total gastrectomy in ECF arm only with $\mathrm{p}=0.000$. Hematologic toxicities were more common in $\mathrm{ECF} p=0.01$. On the other hand, there was no significant difference in progression free survival or overall survival between the three regimens. Modified ECF showed significant overall response than FAM and FLF. However survival benefit is very small. So we recommend using this regimen as neoadjuvant treatment.
\end{abstract}

Keywords: 5-fluorouracil, advanced gastric cancer, ECF, metastatic gastric cancer

\section{Introduction}

Gastric cancer is the fourth most commonly diagnosed cancer and is the second leading cause of cancer death worldwide (Van Cutsem, 2004). Patients with gastric cancer usually present with advanced disease, even after curative resection for patients presenting with early stages, approximately $60 \%$ of these patients eventually relapse locally or with distant metastases (Van Cutsem, 2004). Numerous advances have occurred in the management of gastric cancer, including improvements in diagnosis, histological classification, molecular biology, and treatment, revealed that the role of palliative chemotherapy is therefore of utmost importance (Varadhachary et al., 2005; Crew et al., 2004; Lin et al., 2004). Various chemotherapy combinations have been sought to improve the response rates. Former commonly used regimens include 5-FU, doxorubicin, and mitomycin (FAM); 5- FU, doxorubicin, and high-dose methotrexate (FAMTX); and etoposide, leucovorin, 5-FU (ELF), showed modest effect as regard response rate and survival (Shah et al., 2004), on the other hand epirubicin, cisplatin, and 5-FU (ECF) with protracted infusion of 5-FU resulted in a significant survival benefit when compared with 5-FU and cisplatin in advanced gastric cancer (Cunningham et al., 2006; Cunningham et al., 2008). Moreover several studies reported response rates of over 50\% with ECF, with apparently moderate toxicity and satisfactory symptom control (Ross et al., 2002; Hejna et al., 2006). And when it compared with FAMTX, it showed a higher response rate $(45 \%$ vs $21 \%)$ and longer survival duration (8.9 months vs 5.7 months), with less myelosuppression, less mucositis, and better quality of life (Webb et al., 1997, Sumpter et al., 2005; Lee et al., 2008; Allum et al., 2011; Chan et al., 2011). However, the protracted infusion of 5-FU is expensive, in addition it needs special infusion pump and a well educated patient, consequently, several studied tried to make it convenient either by using 5FU with high dose leucovorin on day 1 and 8 in a cycle repeated every 21 days (Karapetis et al., 2010) or to use it biweekly (Felici et al., 2006) with significant benefits. So we tried to investigate a more convenient modification in this regimen by using 5 days continuous infusion of $5 \mathrm{FU}$ $1000 \mathrm{mg} / \mathrm{m}^{2} /$ day.

So the study was planned to compare the efficacy and tolerability and survival of modified ECF with other regimens (FAM and ELF) which were used in our institute retrospectively. 


\section{Method}

\subsection{Study Design}

The study was performed after obtaining approval from the local Institutional Review Board committee and in accordance with the Declaration of Helsinki, the Good Clinical Practices, and local ethical and legal requirements. The study was performed retrospectively on patients with locally advanced and metastatic adenocarcinoma of esophagogastric junction (OGJ), or stomach treated at South Egypt Cancer Institute, Assiut University, Egypt.

\subsection{Study Population}

The study included 115 Patients who had inoperable esophagogastric junction (OGJ) or stomach with proven histology adenocarcinoma. The primary tumor was classified as inoperable on the basis of findings at computed tomography (CT) scan All patients included were required to have adequate bone marrow function (platelet count $>100 \times 10^{9} / \mathrm{L}$ and $\mathrm{WBC}$ count $>3 \times 10^{9} / \mathrm{L}$ ), creatinine clearance greater than $40 \mathrm{ml} / \mathrm{min}$, bilirubin level less than $30 \mathrm{mmol} / \mathrm{L}$, life expectancy of at least 3 months with no concurrent uncontrolled medical illness and normal left ventricular ejection fraction. Pregnant women were excluded.

\subsection{Methods}

The patients were divided into 3 arms, ECF, FAM and ELF arm

$\boldsymbol{E C F}$ arm; 5-FU was given as a continuous intravenous (IV) infusion at a dose of $1000 \mathrm{mg} / \mathrm{m}^{2} / \mathrm{d}$ for 5 days. Epirubicin $\left(50 \mathrm{mg} / \mathrm{m}^{2} \mathrm{IV}\right)$ and cisplatin $\left(60 \mathrm{mg} / \mathrm{m}^{2}\right)$ IV infusion with standard hydration [8] the regimen was given on an inpatient basis every 3 weeks to a maximum of eight cycles.

FAM regimen; (Hejna et al., 2006) Patients received Mitomycin C $\left(10 \mathrm{mg} / \mathrm{m}^{2}\right)$ IV bolus on day 1, 5-FU (500 $\left.\mathrm{mg} / \mathrm{m}^{2}\right)$ was given by IV bolus on day 1, 8, 22 and 29, doxorubicin $\left(30 \mathrm{mg} / \mathrm{m}^{2}\right) \mathrm{IV}$. For 15 minute on day 1 and 22, Cycles were repeated every 43 days.

ELF regimen; (Moehler et al., 2005) was administered as: leucovorin $\left(300 \mathrm{mg} / \mathrm{m}^{2}\right) \mathrm{I} . \mathrm{V}$. in 10 minutes, followed immediately by etoposide $\left(120 \mathrm{mg} / \mathrm{m}^{2}\right) \mathrm{I}$.V. in 50 minutes and 5 -FU $\left(500 \mathrm{mg} / \mathrm{m}^{2}\right) \mathrm{I}$.V. in 10 minutes, on days 1,2 and 3 , to be repeated on day 22 .

The assessment of responses was classified according scored according to RECIST v1.0 criteria recommendations (Therasse et al., 2000). CT scan and was repeated after 12 and 24 weeks. Only measurable lesions were considered assessable for response evaluation. The toxicity was graded according to NCI-CTC version 2 (Trotti et al., 2000).

\subsection{Statistical Analyses}

The primary endpoint of this study was the overall response rate (ORR); i.e. the percentage of responders (complete response $[\mathrm{CR}]+$ partial response $[\mathrm{PR}]$ ) to treatment. Secondary endpoints included the evaluation of PFS, OS, and the safety profile. The statistical software used in this study was SPSS16. The $\chi^{2}$ test and Fisher's exact test were used to compare the types of response and toxicities in the three treatment groups. Progression free survival and over all survival, were all measured by using the method of Kaplan and Meier (Kaplan et al., 1958). Overall survival was defined as the time interval between the date of randomization and the date of death. Progression-free survival was defined as the time interval between the date of randomization and the date of disease progression or death, whichever occurred first.

$P$ value $<0.05$ were considered significant; all $P$ values are two-sided. Toxicity was evaluated in all of the patients receiving at least one dose of chemotherapy whether they were eligible or not, and was graded according to NCI-CTC version 2.

\section{Results}

\subsection{Patients}

Between July 2005 and June 2010 the patient's files were reviewed retrospectively , 115 patients were included, 60 patients were males and 55 were females, the age of the patients ranged from 25-70 year old, the median age were 53 year old, 18 patients had locally advanced disease, while 97 patients had metastatic disease, all patients had been divided into 3 arms, arm 1 included 41 patients received ECF and arm 2 included 32 patients received FAM, arm 3 included 42 patients received ELF, Patients characteristics are listed in (Table 1). 
Table 1. Patients characteristic in the 3 arms

\begin{tabular}{|c|c|c|c|c|c|c|}
\hline \multirow{2}{*}{ Characteristic } & \multicolumn{2}{|c|}{$\operatorname{ECF}(N=41)$} & \multicolumn{2}{|c|}{$\operatorname{ELF}(N=42)$} & \multicolumn{2}{|c|}{ FAM(N=32) } \\
\hline & $\mathbf{N}$ & $\%$ & $\mathbf{N}$ & $\%$ & $\mathbf{N}$ & $\%$ \\
\hline \multicolumn{7}{|l|}{ Sex } \\
\hline Male & 23 & 56 & 9 & 22 & 28 & 87.5 \\
\hline Female & 18 & 44 & 33 & 78 & 4 & 12.5 \\
\hline \multicolumn{7}{|l|}{ Age "years" } \\
\hline Median & \multicolumn{2}{|c|}{55} & \multicolumn{2}{|c|}{60} & \multicolumn{2}{|c|}{53} \\
\hline Range & \multicolumn{2}{|c|}{$40-70$} & \multicolumn{2}{|c|}{$25-65$} & \multicolumn{2}{|c|}{$26-67$} \\
\hline \multicolumn{7}{|l|}{ Disease extension } \\
\hline Locally advanced & 7 & 17 & 5 & 12 & 6 & 18 \\
\hline Metastatic & 34 & 83 & 37 & 88 & 26 & 82 \\
\hline
\end{tabular}

$\mathrm{N}=$ number

\subsection{Treatment}

The median number of cycles was four (range, one to 8) in the modified ECF arm with total 214 cycles whereas, in FAM arm median number was two (range, one to six) with total 190 cycles. On the hand, median number of cycles was three in ELF (rang one to six) with total 198 cycles, Treatment delay and dose reduction occurred in $25 \%$ and $37 \%$ respectively in patients received ECF arm and $23 \%$ and $35 \%$ in FAM arm $12 \%$ and $33 \%$ in ELF arm, respectively with no significant difference between 3 regimens.

\subsection{Efficacy}

The overall response rate was $36 \%$ (95\% CI: 26.96-42.42) in the modified ECF arm, 16\% (95\% CI: 6.99-23) ELF arm and 15\% (95\% CI: 5.88-21.91) in the FAM arm ( $\mathrm{p}=0.0002)$ (Table 2). Subsequently, symptomatic improvement in the form disappearance of dysphagia and gain of weight occurred in $25 \%$ in ECF which was significantly higher than ELF (9 \%) and FAM (7\%) p=0.001. 4 patients out 7 of with locally advanced gastric cancer in ECF arm were successfully able to undergo total gasterctomy, while, no one in the other arms achieved operability after 3 cycles. On the other hand, there was no statistical difference between 3 groups in patients who had stable disease $\mathrm{p}=0.98$.

Table 2. Response rate

\begin{tabular}{lcccccc}
\hline & \multicolumn{2}{c}{ ECF } & \multicolumn{2}{c}{ ELF } & \multicolumn{3}{c}{ FAM } \\
\cline { 2 - 7 } & $\mathbf{N}$ & $\mathbf{0}$ & $\mathbf{N}$ & $\mathbf{\%}$ & $\mathbf{N}$ & $\mathbf{\%}$ \\
\hline Complete remission & 0 & 0 & 0 & 0 & 0 & 0 \\
Partial remission & 15 & 36.5 & 7 & 16.6 & 5 & 15.6 \\
Stable Disease & 10 & 24.5 & 11 & 26.2 & 8 & 25 \\
Progression of Disease & 11 & 27 & 17 & 40.5 & 16 & 50 \\
Not assable & 5 & 12 & 7 & 16.7 & 4 & 12.4 \\
\hline
\end{tabular}

$\mathrm{N}=$ number

16 patients missed the follow up, five in ECF arm, seven in ELF arm and four in FAM arm, and 4 patients underwent total gastrectomy in ECF arm, so 95 patients were included in the survival data and follow-up evaluation. The median follow-up duration of surviving patients was 16 months. The median progression free survival was 3.2 months for modified ECF 5days, 2 months for FAM and 2.8 months for ELF with p=0.11 (Figure 1) while, the median overall survival time was 7 months with modified ECF, 6 months with FAM 6.8 months for ELF ( $\mathrm{p}=0.42)$ (Figure 2). 


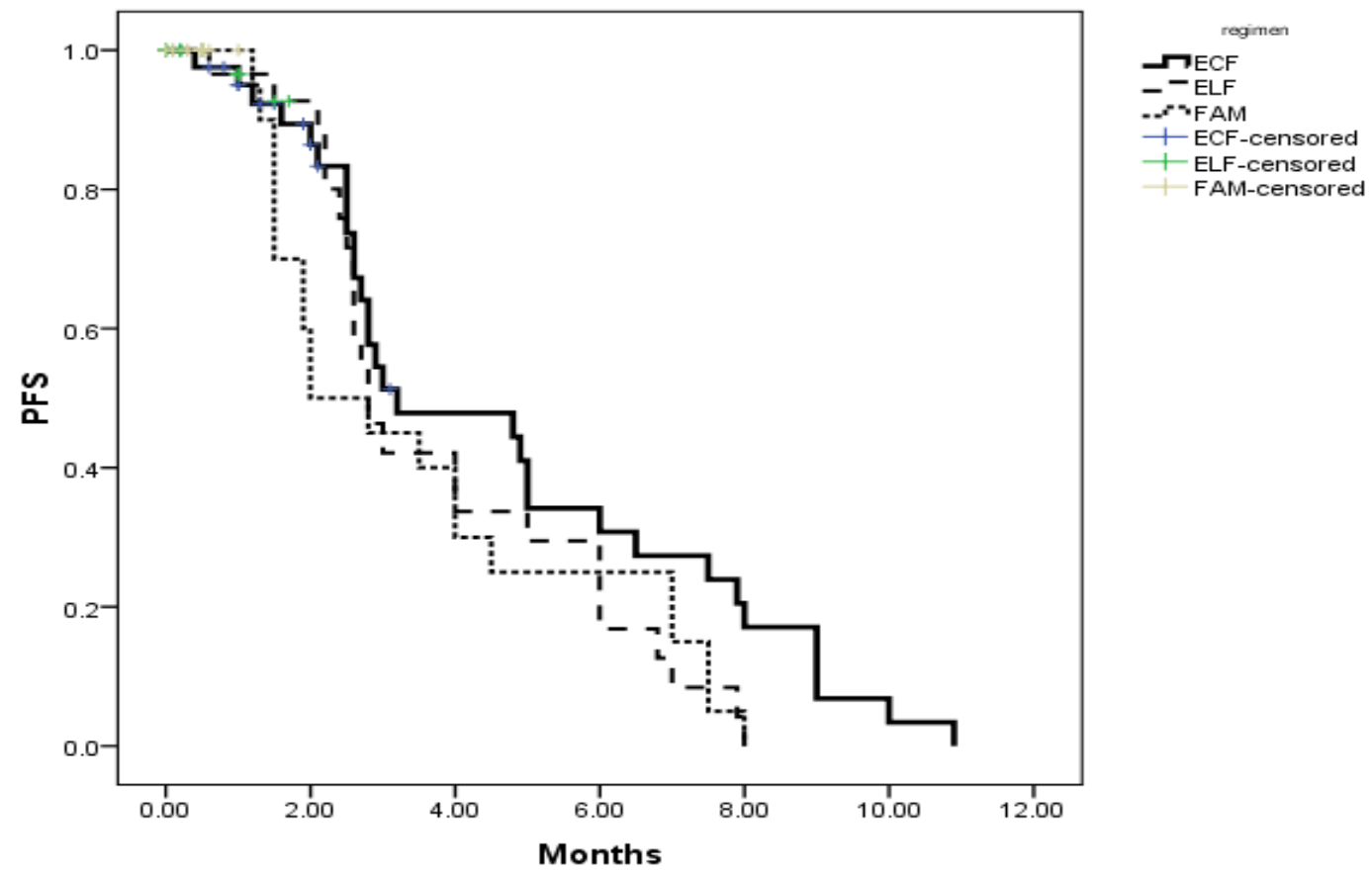

\begin{tabular}{|lllc|}
\hline No of patients & Censored & Events & Median PFS \\
115 & $\mathbf{2 0}(17.4 \%)$ & $95(82.6 \%)$ & 3.2 m for ECF, 2.8m for ELF, 2 for FAM \\
\hline
\end{tabular}

Figure 1. Progression free survival for modified ECF, ELF and FAM
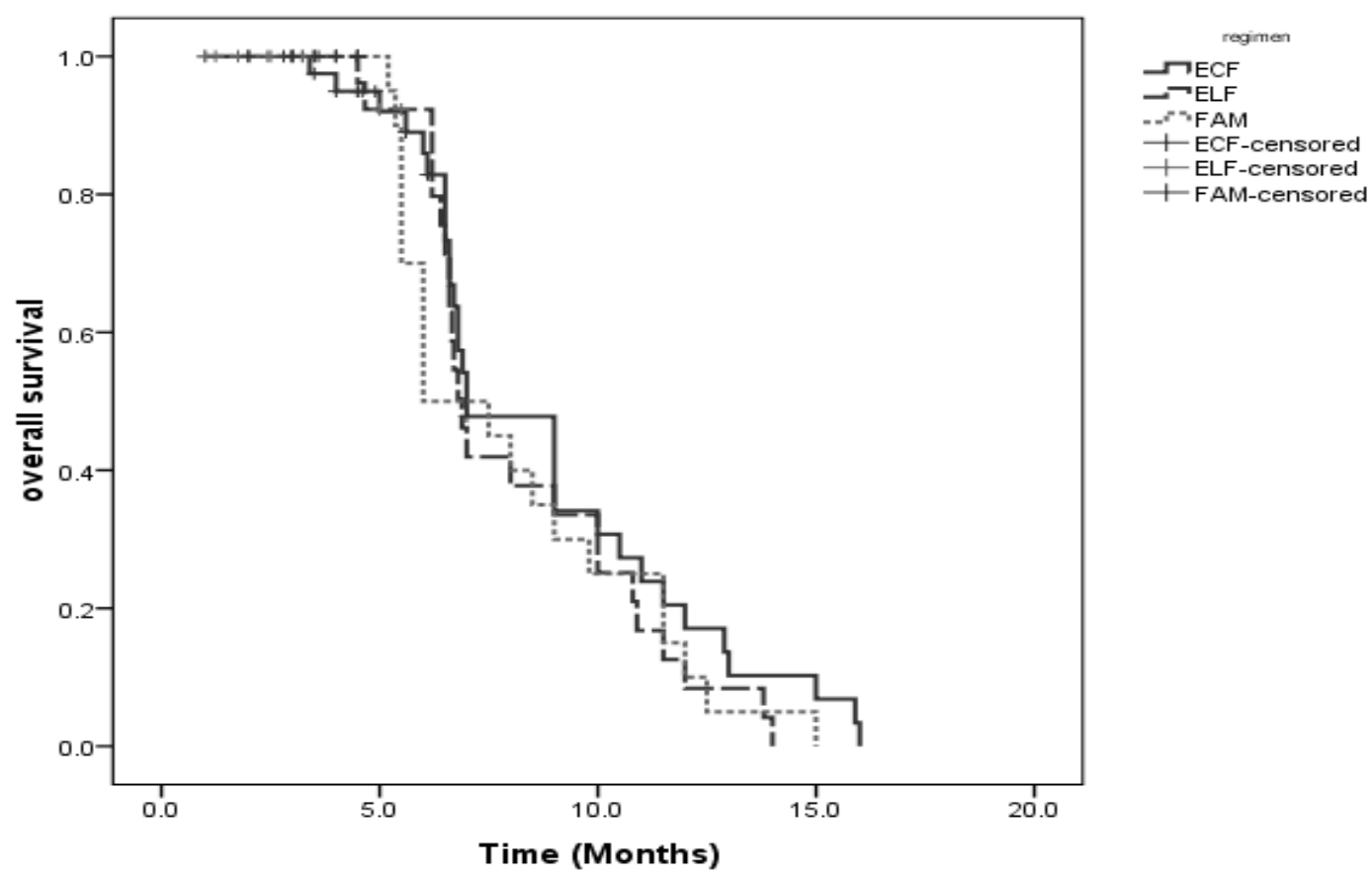

\begin{tabular}{|llll|}
\hline No of patients & Censored & Events & Median OS \\
115 & $20(17.4 \%)$ & $\mathbf{9 5 ( 8 2 . 6 \% )}$ & 7mfor ECF, 6m for ELF, 6.8 for FAM \\
\hline
\end{tabular}

Figure 2. Overall survival for modified ECF, ELF and FAM 


\subsection{Gastrectomy after Chemotherapy}

Four patients who presented with locally advanced in modified ECF arm were able to have total gastrectectomy after 3 cycles of chemotherapy, R0 resection was feasible in all 4 patients. Survival rates at one and two year after surgery were $100 \%$ and $75 \%$, respectively. Two patients were disease-free at 28 and 30 months after surgery. 2 patients had recurrence after a median follow up of 12 months and 16 months following surgery.

\subsection{Safety}

Toxicities of the 3 regimens are listed in (Table 3). The ECF regimen resulted in significant mucositis and grade IV neutropenia $\mathrm{P}=0.01,11$ patients in ECF arm required hospital admission; 6 of them due to grade IV oral mucosites and the other 5 patients admitted due to febrile neutropenia, whereas in FAM arm only 4 patients required admission; 1 due to grade IV oral mucosities and 3 due to febrile neutropenia, on the other hand in ELF arm, all side effects were managed in out patients clinic. There were three toxic deaths (one in modified ECF in $4^{\text {th }}$ cycle and two in FAM in $2^{\text {nd }}$ and $4^{\text {th }}$ cycle respectively), all due to neutropenic sepsis. Totally ECF regimen had significant side effect $\mathrm{p}=0.04$ compared with FAM and ELF.

Table 3 . Worst toxicity associated with 3 regimens

\begin{tabular}{rccccccc}
\hline Toxicity & \multicolumn{2}{c}{ ECF } & \multicolumn{2}{c}{ ELF } & \multicolumn{3}{c}{ FAM } \\
\cline { 2 - 8 } Neutropenia(GI-II) & 10 & 24 & $\mathbf{N}$ & $\%$ & N & $\%$ \\
Neutropenia(GIII-IV) & 16 & 39 & 3 & 4 & 7 & 12.5 \\
Thrombocytopenia(GIII-IV) & 14 & 34 & 3 & 7 & 8 & 25 & 25 \\
Infection & 7 & 17 & 9 & 21 & 6 & 18 \\
Nausea/vomiting(GII-III) & 20 & 48 & 6 & 14 & 20 & 62 \\
Mucositis(GIII-IV) & 17 & 31 & 12 & 28 & 8 & 25 \\
Diarrhea(GII-III) & 7 & 17 & 8 & 25 & 4 & 12.5 \\
\hline
\end{tabular}

$\mathrm{G}=\mathrm{Grade}$

\section{Discussion}

Combination regimens with 5-FU and cisplatin showed promising activity in Phase II trials and are frequently used throughout Europe. Epirubicin was included in this combination because of anticipated enhanced cytotoxicity (Sumpter et al., 2005; Lee et al., 2008; Allum et al., 2011; Chan et al., 2011). Consequently the combination Epirubicin, cisplatin and 5-FU (ECF) in a randomized Phase III study showed superior response rates and significantly prolonged survival when compared with the historic reference regimen 5-FU, doxorubicin and methotrexate (FAMTX) (Webb et al., 1997; Sumpter et al., 2005; Lee et al., 2008; Allum et al., 2011; Chan et al., 2011). Therefore, the ECF regimen has represented a step ahead in the treatment of advanced gastric cancer. Despite higher response rates and lower toxicity, a potential drawback of the ECF regimen may be the poor patient acceptability of the indwelling catheter and presence of the external infusion pump (Ozkan et al., 2005). As an alternative, some European investigators have adopted the use of weekly or biweekly 24 to 48 -hour infusions of 5-FU to ease the administration of treatment (Felici et al., 2006) or used 5-FU with high dose sodium folinate (Karapetis et al., 2010).

To reduce the catheter line-associated morbidity for non educated patients and to make it more convenient for our patients, we modified this regimen and administered 5-FU as a continuous infusion with dose of $1000 \mathrm{mg} / \mathrm{m}^{2}$ for 5 days.

In our study, we selected the patients with clearly measurable disease (eg, hepatic metastasis or lymph nodes) to be assessed for objective remissions.

Based on that, we found that the overall response observed in 36\%, ECF which is clearly more superior to ELF $16 \%$, and FAM (15\%). Which lead to symptomatic improvement in $25 \%$ in ECF and it was significantly higher than ELF (9\%) and FAM (7\%).

Also this achievement of considerable overall response successfully changed 4 patients with locally advanced gastric cancer to operable tumors after 3 cycles of ECF regimen. 
But this significant overall response was associated with significant hematological toxicity $p=0.01$ so we modified our regimen to be used with colony stimulating factor from second cycle if the patient experienced hematological toxicity of grade III. Furthermore, this significant improvement in the response didn't convert to improvement in overall survival $\mathrm{p}=0.42$.

On the other hand, when we compared the efficacy of our modified ECF regimen with other regimens which used ECF with adjustment of the dose of 5FU, we found that the overall response of $36 \%$ with our modified ECF regimen was superior to modified ECF regimen used by (Ozkan et al., 2005) as they used short infusion of 5FU for 5 days but with dose $300 \mathrm{mg} / \mathrm{m}^{2}$ for 5 days. on the contrary, our regimen was inferior to (Karapetis et al., 2010 ) who used with 5 -FU $\left(1750 \mathrm{mg} / \mathrm{m}^{2}\right)$ and sodium folinate $\left(500 \mathrm{mg} / \mathrm{m}^{2}\right)$ administered as a 24-hour infusion on day 1 and day 8 .

In conclusion, ECF with continuous Infusion 5-FU for 5 days appears to be tolerated and demonstrated activity in advanced and metastatic cancer stomach. And it is possible to administer it through a peripheral venous line; this makes this regimen safer and more acceptable to patients. However, it didn't improve the overall survival so we suggest it could be used as neo-adjuvant regimen and further study to assess its efficacy as neo-adjuvant regimen for locally advanced cancer stomach is recommended.

\section{References}

Allum, W. H., Blazeby, J. M., Griffin, S. M., Cunningham, D., Jankowski, J. A., \& Wong, R. (2011). Guidelines for the management of oesophageal and gastric cancer. Gut, 60(11), 1449-1472. http://dx.doi.org/10.1136/gut.2010.228254

Chan, J. A., Blaszkowsky, L. S., Enzinger, P. C., Ryan, D. P., Abrams, T. A., Zhu, A. X., ... Fuchs, C. S. (2011). A multicenter phase II trial of single-agent cetuximab in advanced esophageal and gastric adenocarcinoma. Ann Oncol, 22(6), 1367-73. http://dx.doi.org/10.1093/annonc/mdq604

Crew, K. D., \& Neugut, A. I. (2004). Epidemiology of upper gastrointestinal malignancies. Semin Oncol, 31, 450-464. http://dx.doi.org/10.1053/j.seminoncol.2004.04.021

Cunningham, D., Allum, W. H., Stenning, S. P., Thompson, J. N., Van de Velde, C. J., Nicolson, M., ... Chua, Y. J., MAGIC Trial Participants. (2006). MAGIC Trial Participants. Perioperative chemotherapy versus surgery alone for resectable gastroesophageal cancer. $N$ Engl $J$ Med, 355(1), 11-20. http://dx.doi.org/10.1056/NEJMoa055531

Cunningham, D., Starling, N., Rao, S., Iveson, T., Nicolson, M., \& Coxon, F. (2008). Capecitabine and oxaliplatin for advanced esophagogastric cancer. $N$ Engl $J$ Med, 358(1), 36-46. http://dx.doi.org/10.1056/NEJMoa073149

Felici, A., Carlini, P., Ruggeri, E. M., Gamucci, T., Pollera, C. F., De Marco, S., ... Cognetti, F. (2006). Bi-weekly chemotherapy with cisplatin, epirubicin, folinic acid and 5-fluororacil continuous infusion plus g-csf in advanced gastric cancer: a multicentric phase II study. Cancer Chemother Pharmacol, 57(1), 59-64. http://dx.doi.org/10.1007/s00280-005-0032-5

Hejna, M., Wöhrer, S., Schmidinger, M., \& Raderer, M. (2006). Postoperative chemotherapy for gastric cancer. The Oncologist, 11(2), 136-45. http://dx.doi.org/10.1634/theoncologist.11-2-136

Kaplan, E. L., \& Meier, P. (1958). Nonparametric estimation from incomplete observations. J Am Stat Assoc, 53, 457-481. http://dx.doi.org/10.1080/01621459.1958.10501452

Karapetis, C. S., Cheong, K. A., Yip, D., Strickland, A. H., Steer, C., Marx, G., ... Harper, P. G. (2010). Phase I and II trial of epirubicin, cisplatin, 24-hour infusion 5 fluorouracil and sodium folinate in patients with advanced esophagogastric carcinomas. Asia-Pacific Journal of Clinical Oncology, 6, 298-305. http://dx.doi.org/10.1111/j.1743-7563.2010.01340.x

Lee, J. L., Kang, Y. K., Kang, H. J., Lee, K. H., Zang, D. Y., Ryoo, B. Y., ... Min, Y. J. (2008). A randomised multicentre phase II trial of capecitabine vs S-1 as first-line treatment in elderly patients with metastatic or recurrent unresectable gastric cancer. Br J Cancer, 99(4), 584-90. http://dx.doi.org/10.1038/sj.bjc.6604536

Lin, J., \& Beerm, D. G. (2004). Molecular biology of upper gastrointestinal malignancies. Semin Oncol, 31, 476-486. http://dx.doi.org/10.1053/j.seminoncol.2004.04.019

Moehler, M., Eimermacher, A., Siebler, J., Höhler, T., Wein, A., Menges, M., ... Heike, M. (2005). Randomised phase II evaluation of irinotecan plus high-dose 5-fluorouracil and leucovorin (ILF) vs 5-fluorouracil, 
leucovorin, and etoposide (ELF) in untreated metastatic gastric cancer. $\mathrm{Br} J$ Cancer, 92(12), 2122-8. http://dx.doi.org/10.1038/sj.bjc.6602649

Ozkan, K., Turkkan, E., Ender, K., Mutlu, D., Murat, A., Nalan, B., Abdulmecit, Y., \& Osman, M. (2005). 5-Fluorouracil, epirubicin and cisplatin in the treatment of metastatic gastric carcinoma: a retrospective analysis of 68 patients. Indian J Cancer, 42(2), 85-8. http://dx.doi.org/10.4103/0019-509X.16697

Ross, P., Nicolson, M., Cunningham, D., Valle, J., Seymour, M., Harper, P., ... Norman, A. (2002). Prospective randomized trial comparing mitomycin, cisplatin, and protracted venous-infusion fluorouracil (PVI 5-FU) with epirubicin, cisplatin, and PVI 5-FU in advanced esophagogastric cancer. J Clin Oncol, 20(8), 1996-2004. http://dx.doi.org/10.1200/JCO.2002.08.105

Shah, M. A., \& Schwartz, G. K. (2004). Treatment of metastatic esophagus and gastric cancer. Semin Oncol, 31, 574-587. http://dx.doi.org/10.1053/j.seminoncol.2004.04.013

Sumpter, K., Harper-Wynne, C., Cunningham, D., Rao, S., Tebbutt, N., Norman, A. R., ... Oates, J. (2005). Report of two protocol planned interim analyses in a randomised multicentre phase III study comparing capecitabine with fluorouracil and oxaliplatin with cisplatin in patients with advanced oesophagogastric cancer receiving ECF. Br J Cancer, 92(11), 1976-83. http://dx.doi.org/10.1038/sj.bjc.6602572

Therasse, P., Arbuck, S. G., Eisenhauer, E. A., Wanders, J., Kaplan, R. S., Rubinstein, L., ... Gwyther, S. G. (2000). New guidelines to evaluate the response to treatment in solid tumors. European Organization for Research and Treatment of Cancer, National Cancer Institute of the United States, National Cancer Institute of Canada. J. Natl. Cancer Inst., 92, 205-216. http://dx.doi.org/10.1093/jnci/92.3.205

Trotti, A., Byhardt, R., Stetz, J., Gwde, C., Corn, B., Fu, K., ... Curran, W., Radiation Therapy Oncology Group. (2000). Related Articles, Links Common toxicity criteria: version 2.0. an improved reference for grading the acute effects of cancer treatment: impact on radiotherapy. Int $J$ Radiat Oncol Biol Phys, 47, 13-47. http://dx.doi.org/10.1016/S0360-3016(99)00559-3

Van Cutsem, E. (2004). The treatment of advanced gastric cancer: new findings on the activity of the taxanes. The Oncologist, 9(suppl 2), 9-15. http://dx.doi.org/10.1634/theoncologist.9-suppl_2-9

Varadhachary, G. R., \& Ajani, J. A. (2005). Gastric cancer. Clin Adv Hematol Oncol, 3, 118-124.

Webb, A., Cunningham, D., Scarffe, J. H., Harper, P., Norman, A., Joffe, J. K., ... Meehan, M. (1997). Randomized trial comparing epirubicin, cisplatin, and fluorouracil versus fluorouracil, doxorubicin, and methotrexate in advanced esophagogastric cancer. J Clin Oncol, 15, 261-7. 